\title{
Activation of TRPVI in the VTA Excites Dopaminergic Neurons and Increases Chemical- and Noxious-Induced Dopamine Release in the Nucleus Accumbens
}

\author{
Silvia Marinelli*,', Tiziana Pascucci' ${ }^{2,3}$, Giorgio Bernardi ${ }^{1,4}$, Stefano Puglisi-Allegra ${ }^{2,3}$ and Nicola B Mercuri ${ }^{1,4}$ \\ 'Laboratorio di Neurologia Sperimentale, IRCCS Fondazione Santa Lucia, Italy; 'Dipartimento di Psicologia, Università 'La Sapienza', Italy; \\ ${ }^{3}$ Laboratorio di Neurobiologia del Comportamento, Fondazione Santa Lucia, Italy; 'Dipartimento di Neuroscienze, Università 'Tor Vergata', \\ Rome, Italy
}

\begin{abstract}
Dopamine (DA)-containing neurons of the ventral tegmental area (VTA) provide dopaminergic input to the nucleus accumbens and to the prefrontal cortex within the mesolimbic pathway. In the present study, we combined electrophysiological recordings and microdialysis techniques to investigate the function of transient receptor potential vanilloid I (TRPVI) channel in the VTA. In brain slices, application of the TRPVI receptor agonist capsaicin increased the firing rate of rat dopamine neurons and in a proportion of tested cells (44\%) it also induced a bursting behavior. The effects of capsaicin were concentration dependent. The increase in neuronal firing was dependent on enhanced glutamatergic transmission since it was blocked by the superfusion of the ionotropic glutamate antagonists, CNQX and AP5. Interestingly, microinjection of capsaicin into the VTA and noxious tail stimulation transiently enhanced dopamine release into the nucleus accumbens. Both the in vitro and in vivo effects were mediated by TRPVI activation in the VTA since they were reduced by co-perfusion of the selective TRPVI receptor antagonist iodoresineferatoxin. Our data suggest a novel role for TRPVI channels in the mesencephalon of rat, namely activation of the DA system following a peripheral noxious stimulation. Neuropsychopharmacology (2005) 30, 864-870, advance online publication, 24 November 2004; doi:10.1038/sj.npp. 1300615
\end{abstract}

Keywords: mesolimbic area; noxious stimulation; dopamine; capsaicin; patch-clamp recordings; microdialysis

\section{INTRODUCTION}

The dopaminergic (DA) neurons of the ventral tegmental area (VTA), together with its afferents to the nucleus accumbens (NAc) and to the prefrontal cortex (PFC), constitute a crucial neuronal system that processes natural rewards (Hollerman and Schultz, 1998; Schultz, 1986; Di Chiara et al, 1993; Schmidt, 1998; Wise, 2002) and drug-seeking behavior (Phillips et al, 2003; Bonci et al, 2003). However, several studies have shown that VTA DA neurons can also be involved in acute stress responses (Maeda and Mogenson, 1982; Mantz et al, 1989; Gao et al, 1990), which cause an increase of DA efflux into the output areas (Cabib and Puglisi-Allegra, 1994; Horger and Roth, 1996; Finlay and Zigmond, 1997; Guarraci and Kapp, 1999). These studies suggest that changes in the activity of

*Correspondence: Dr S Marinelli, Laboratorio Neurologia Sperimentale, IRCCS-Fondazione Santa Lucia, Via Ardeatina 306, 00179 Rome, Italy, Tel: + 3906 5I50I382, Fax: + 3906 51501384,

E-mail: s.marinelli@hsantalucia.it

Received 6 July 2004; revised 2 I September 2004; accepted 5 October 2004

Online publication: I I October 2004 at http://www.acnp.org/citations/ Npp 101 1 04040309/default.pdf
DA neurons are potential indicators of the responses of these cells either to pleasant, or to noxious stimuli (Moore et al, 2001), and are strictly controlled by excitatory and inhibitory inputs (Overton and Clark, 1997; Grillner and Mercuri, 2002; Prisco et al, 2002; Floresco et al, 2003).

Recently, we have shown that the vanilloid receptor (TRPV1), which belongs to the transient receptor potential channel family, increases glutamatergic transmission onto midbrain DA neurons (Marinelli et al, 2003), suggesting that TRPV1 activation can increase cellular excitation of these cells.

Besides the control of synaptic transmission in the brain (Sasamura et al, 1998; Doyle et al, 2002; Marinelli et al, 2002, 2003), the TRPV1 channels are also known to be involved in mediating nociceptive and stressful processes in the peripheral nervous system (O'Neil and Brown, 2003).

Therefore, we performed in vitro and in vivo experiments aimed to investigate the role of TRPV1 channels in modulating DA release in the mesolimbic system, either in response to direct activation of TRPV1 by local capsaicin or by peripheral noxious stimulation of the tail in freely moving rats. 


\section{METHODS}

\section{Slice Preparation}

Wistar rats, 2-3-weeks old, were anesthetized by halothane and killed by decapitation. The brain was rapidly removed from the skull and horizontal brain stem slices $(300 \mu \mathrm{M})$ were cut in cold $\left(8-12^{\circ} \mathrm{C}\right)$ artificial cerebrospinal fluid (ACSF), using a vibratome, and left to recover at $33^{\circ} \mathrm{C}$ for at least $1 \mathrm{~h}$. Slices were separately placed in a recording chamber and submerged in a continuously flowing $(3 \mathrm{ml} /$ min, $34^{\circ} \mathrm{C}$ ) ACSF. ACSF composition was (in $\mathrm{mM}$ ): $\mathrm{NaCl}$ 126; $\mathrm{KCl}$ 2.5; $\mathrm{MgCl}_{2}$ 1.2; $\mathrm{CaCl}_{2}$ 2.4; $\mathrm{NaH}_{2} \mathrm{PO}_{4}$ 1.2; $\mathrm{NaHCO}_{3}$ 24; glucose 10 .

\section{Electrophysiology}

The neurons were visualized using infrared Nomarski optics mounted on an upright microscope (Olympus BX50WI) and equipped with infrared-DIC enhancement. Patch-clamp recordings in whole-cell and cell-attached mode were obtained with glass electrodes (3.7-4 M $\Omega$ ) filled with (in $\mathrm{mM}$ ): K-gluconate 145; $\mathrm{MgCl}_{2} 2 ; \mathrm{CaCl}_{2}$ 0.1; EGTA 0.75; HEPES 10 ; MgATP 2 mM; $\mathrm{Na}_{3}$ GTP 0.3 (pH 7.3, with KOH) and using an Axopatch 1D (Axon Instruments) ( $I=$ clamp and $I=0$ in whole-cell and cell-attached mode, respectively). Acquisition of spikes was filtered at $1 \mathrm{kHz}$, digitized at $10 \mathrm{kHz}$, and acquired on a PC by means of Axoscope 9 software (Axon Instruments).

Whole-cell patch-clamp recordings were obtained from 21 VTA DA neurons, which were identified using wellestablished criteria, such as spontaneous single-pacemaker firing at $1-3 \mathrm{~Hz}$, hyperpolarization of the membrane potential in response to exogenous application of dopamine and the presence of a hyperpolarization-activated inward current $\left(I_{h}\right)$ in response to voltage steps to $-100 \mathrm{mV}$, from a holding potential of $-60 \mathrm{mV}$ (Grace and Onn, 1989; Johnson and North, 1992; Mercuri et al, 1995).

\section{Firing Analyses}

The firing activity and burst events were detected and analyzed with Clampfit 9 software (Axon Instruments). The mean firing frequency (in $\mathrm{Hz}$ ) of each neuron was determined over a time period during which cell firing had stabilized (usually 2-3 min). For the evaluation of capsaicin effect, the last two minutes of capsaicin application and first two minutes of wash out were analysed.

Changes of membrane potential in spontaneously active DA cells were detected by measuring membrane potential values between spikes (see the asterisk on the vertical and horizontal dashed lines in Figure 1a, left panel).

For burst analyses, we chose an appropriate number of action potential (3-4 at least), together with a burst delimiting interval of $300 \mathrm{~ms}$ (Prisco et al, 2002). A burst of spikes was superimposed on a depolarizing phase (envelope) of the membrane potential that advances and terminates when the membrane potential is driven into a temporary state of depolarization block (see the inset of Figure 1a, Shepard and Bunney, 1991).

The data in the text are given as mean \pm SEM and as percentage of control. Statistical differences were determined on the raw data by using paired Student's $t$-test. a

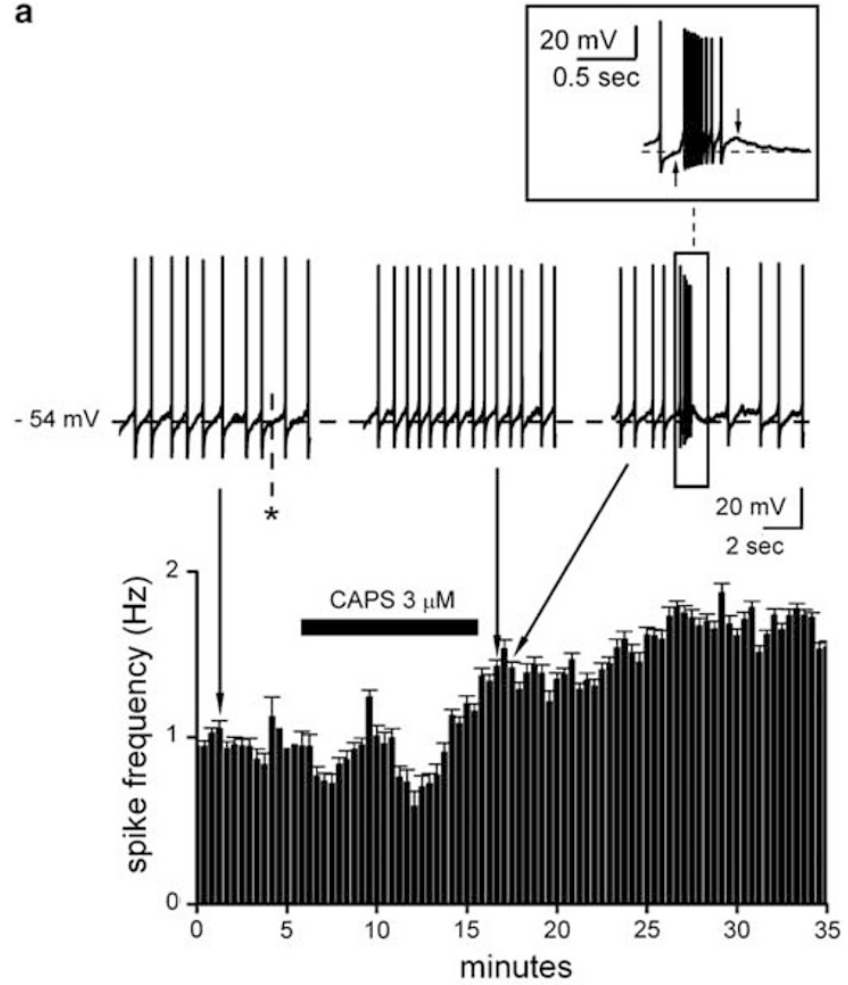

b

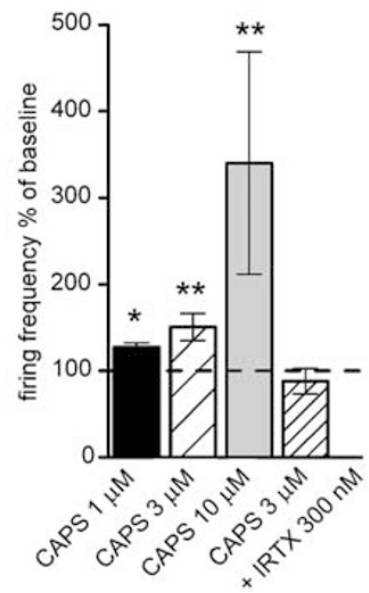

Figure I Excitatory effects of capsaicin on the firing activity of a VTA dopamine neuron. (a) Top, raw traces of whole-cell current-clamp recordings from a single neuron in control condition (left panel), during bath application of CAPS (middle panel) and CAPS-induced burst discharge (right panel). The trace in the inset shows at a larger view the action potentials superimposed in the depolarizing envelope delimiting the depolarization. Note that the arrows indicate the initiation and peak of the depolarization. The dotted line between spikes indicated an extrapolated value of potential below spike threshold- $54 \mathrm{mV}$. Bottom, running spike frequency histogram of the same neuron shown at the points indicated by the arrows. Note the irreversible effect of CAPS on firing activity. (b) Histogram summarizing CAPS effects $(1-3-10 \mu \mathrm{M})$ as percentage change of firing activity and the antagonism of CAPS $(3 \mu \mathrm{M})$ effects in the presence of IRTX $(p>0.05)$. $* p<0.05$, *** $p<0.01$.

\section{Animals}

Male Wistar rats (175-200 g; Charles River, Italy) were housed in groups of three per cage and maintained in an air-conditioned room at $21 \pm 1^{\circ} \mathrm{C}$, on a 12-h light-dark cycle 
(0700-1900 h) with food and water ad libitum for at least 10 days before use.

All animals were tested between 1000 and $1700 \mathrm{~h}$ and were exposed individually to one experiment only.

The procedures used in this study were in strict accordance with the European legislation (EEC no. 86/ 609), the Italian national legislation (DL no. 116/92) governing the use of animals for research, and with the guidelines of the National Institutes of Health on the use and care of laboratory animals reported.

\section{Microdialysis}

Animals were anesthetized with an intraperitoneal injection of ketamine/xylazine $(80: 10 \mathrm{mg} / \mathrm{kg})$, mounted in a stereotaxic frame (David Kopf Instrument, Tujunga, CA) and implanted unilaterally with a guide cannula (stainless steel; shaft $\mathrm{OD}, 0.38 \mathrm{~mm}$; length $6.5 \mathrm{~mm}$ Metalant $\mathrm{AB}$, Stockholm, Sweden) in NAc and VTA. The length of the guide cannula was $6 \mathrm{~mm}$ for NAc and $7.5 \mathrm{~mm}$ for VTA. The guide cannula was fixed with epoxy glue and dental cement was added for additional stabilization. The coordinates from the bregma (measured according to the atlas of Paxinos and Watson (1982)) were (in $\mathrm{mm}$ ): $+1.7 \mathrm{AP},-0.9 \mathrm{~L}$ for NAc and $-5 \mathrm{AP}$, $-0.7 \mathrm{~L}$ for VTA. At the end of surgery, animals were housed individually into a new home cage adapted to avoid the breaking of the implantation.

The following day, rats were lightly anesthetized to facilitate insertion of the microdialysis probe (dialysis membrane length $2 \mathrm{~mm}$; OD of $0.24 \mathrm{~mm}$, MAB4 cuprophane microdialysis probe, Metalant $\mathrm{AB}$ ) into the guide cannula of the NAc.

Immediately after implantation, microdialysis probe was connected via polyethylene- 20 tubing and a dual-channel swivel (model 375/D/22QM; Instech Laboratories, Plymouth Meeting, PA) to a syringe of a CMA/100 pump (Carnegie Medicine, Stockholm, Sweden) and perfused with artificial CSF (in mM: $147 \mathrm{NaCl}, 2.2 \mathrm{CaCl}_{2}$, and $4 \mathrm{KCl}$ ) (Pontieri et al, 1995) at a constant flow rate of $2 \mu \mathrm{l} / \mathrm{min}$ for at least $2 \mathrm{~h}$. Experiments were performed $24 \mathrm{~h}$ after probe placement. During experiment, each rat was left in its home cage and microdialysis probe was connected to the pump. After the start of dialysis perfusion, rats were left undisturbed for $2 \mathrm{~h}$ before collection of baseline samples. Four baseline samples before treatment were collected. The dialysate was collected every $8 \mathrm{~min}$ for $120 \mathrm{~min}$ post-treatment, and a volume of $10 \mu \mathrm{l}$ was analyzed by HPLC system to quantify the dopamine levels, as described previously (Ventura et al, 2003). Briefly, the HPLC system consisted of an Alliance (Waters Corporation, Milford, MA) and a coulometric detector (model 5200A Coulochem II; ESA, Chelmsford, MA). A conditioning cell ( $+400 \mathrm{mV}$; ESA; model 5021$)$ was placed immediately after a C18 column $(3.9 \times 150 \mathrm{~mm}$; Waters Corporation), and followed by an analytical cell (electrode 1 at $+200 \mathrm{mV}$, and electrode 2 at -250 ; ESA; model 5011). The column was maintained at $33^{\circ} \mathrm{C}$; the flow rat was $1.2 \mathrm{ml} / \mathrm{min}$. The mobile phase was as described previously (Westerink et al, 1998). Peak height produced by reduction of DA was compared with that produced by a standard. The detection limit of assay was $0.1 \mathrm{pg}$.

Vehicle (CSF plus ethanol) or iodoresineferatoxin $1 \mu \mathrm{M}$ (IRTX, $0.2 \mu \mathrm{l} / 2 \mathrm{~min}$ ) was injected into VTA through a stainless-steel cannula $(0.15 \mathrm{~mm}$ OD; $8 \mathrm{~mm}$ lenght; UNIMED, Switzerland) connected to a $1 \mu \mathrm{l}$ syringe by a polyethylene tube and driven by a CMA/100 pump. The cannula was left in place for an additional $2 \mathrm{~min}$ after the end of infusion. At $15 \mathrm{~min}$ after the first injection, rats that were injected by vehicle received another injection of vehicle (veh + veh group) or capsaicin (CAPS) $50 \mu \mathrm{M}$ (veh + CAPS group) by the same system; while rats injected by IRTX received CAPS $50 \mu \mathrm{M}$ (IRTX + CAPS group) or again IRTX. Half of the rats in the veh + veh group and rats injected twice by IRTX were exposed to tail-shock stress (veh + shock and IRTX + shock groups) immediately after the second injection. Tail shock $(3 \mathrm{~s}, 0.50 \mathrm{~mA})$ was administered through stainless steel electrodes applied to the tail.

\section{Statistical Analysis}

The effects of CAPS and IRTX + CAPS on extracellular DA levels in the NAc were analyzed by repeated-measures ANOVA with one between factor (treatment, three levels: veh, CAPS and IRTX + CAPS) and one within factor (time, six levels: $0,8,16,24,32,40 \mathrm{~min}$ from drug injection, $n=15)$.

The effects of shock and IRTX + shock on accumbal DA release were analyzed by repeated-measures ANOVA with one between factor (treatment, two levels: shock and IRTX + shock) and one within factor (time, eight levels: $0,8,16$, $24,32,40,48,56 \mathrm{~min}(n=10))$. Simple effects were assessed by one-way ANOVA for each time point. Individual between-group comparisons, when appropriate, were performed by post hoc test (Duncan's multiple range test).

\section{Drug Application}

For the electrophysiological experiments, drugs were bath applied at the following concentration: CAPS, $1-3-10 \mu \mathrm{M}$, IRTX, $300 \mathrm{nM}, \mathrm{D}-(-)-2-$ Amino-5-phosphonopentanoic acid (D-AP5, $50 \mu \mathrm{M}$ ), and 6-cyano-7-nitroquinoxaline-2,3-dione disodium (CNQX, $10 \mu \mathrm{M})$. CAPS and IRTX were dissolved in DMSO and the final concentration of the vehicle was less than $0.05 \%$, which was devoid of any effects. For these reasons, we considered control conditions as those with and without vehicle. Each slice received only a single exposure to CAPS. All these drugs were purchased from Tocris (UK), except for dopamine that was obtained from Sigma.

For microdialysis experiments, both IRTX $(1 \mu \mathrm{M})$ and CAPS $(50 \mu \mathrm{M})$ were dissolved in $100 \%$ ethanol and later diluted in artificial CSF (in mM: $147 \mathrm{NaCl}, 2.2 \mathrm{CaCl}_{2}$, and 4 $\mathrm{KCl}$ ). The CAPS and IRTX doses were selected on the basis of preliminary experiments. For CAPS we found that $50 \mu \mathrm{M}$ was a threshold dose in a range going from 25 to $200 \mu \mathrm{M}$, while for IRTX we observed an antagonist effect at $1 \mu \mathrm{M}$, a threshold dose in a range going from $300 \mathrm{nM}$ to $10 \mu \mathrm{M}$.

\section{RESULTS}

\section{Capsaicin Increases the Firing Activity of VTA Dopamine Neurons}

Since we have previously shown that CAPS increases glutamatergic synaptic transmission onto midbrain DA 
neurones (Marinelli et al, 2003), in this study we tested whether the activation of TRPV1 could affect the firing of spontaneously active DA cells in the VTA.

In whole-cell current-clamp recordings, bath application of the TRPV1 agonist CAPS $(1 \mu \mathrm{M})$ caused a significant increase of the firing rate of DA neurons from $1.12 \pm 0.46$ to $1.44 \pm 0.59 \mathrm{~Hz}(27.50 \pm 4 \%, p<0.05, n=4$, Figure $1 \mathrm{~b})$ without affecting the membrane potential. The effect of CAPS was dose-dependent. CAPS $3 \mu \mathrm{M}$ increased the firing frequency by $46 \%$ of control, from $1.30 \pm 0.59$ to $1.76 \pm 0.41 \mathrm{~Hz}(n=5, p<0.01$, Figure $1 \mathrm{a}, \mathrm{b})$ and $10 \mu \mathrm{M}$ raised the firing rate to $240 \%$ (from $1.83 \pm 0.72$ to $3.84 \pm 0.65 \mathrm{~Hz} ; n=4, p<0.01$, Figure $1 \mathrm{~b})$. The interspike membrane potential was slightly depolarized by CAPS 3 and $10 \mu \mathrm{M} \quad(3.20 \pm 1.63$ and $3.83 \pm 1 \mathrm{mV}$, respectively). The increase in firing had a slow onset and fully developed at the end of perfusion (5-10 min).

In four out of nine neurons, superfusion of $3-10 \mu \mathrm{M}$ CAPS caused a depolarizing envelope $(9.76 \pm 0.79 \mathrm{mV})$ and bursts of action potentials ( $12.80 \pm 1.28$ spikes in a burst, $126 \pm 70 \mathrm{~ms}$ intraburst interval, $1441.46 \pm 773 \mathrm{~ms}$ burst duration). The interburst interval was irregular and could vary from 11 to $59 \mathrm{~s}(30.82 \pm 9.75 \mathrm{~s})$ (Figure 1a).

The effect of CAPS on the firing activity of dopamine neurons has been also investigated by using single-unit recordings. Application of CAPS $3 \mu \mathrm{M}$ caused a significant increase in the spike frequency by $21.90 \pm 8.68 \%$, from $3.33 \pm 1.01$ to $4.05 \pm 1.03 \mathrm{~Hz}(n=5, p<0.05)$ and in two out of five DA neurons we observed bursts of spikes (data not shown).

\section{The Increase in Firing Rate was TRPV1-Mediated and Glutamate-Dependent}

To confirm that the increased frequency of firing induced by CAPS was mediated by the activation of TRPV1, we performed experiments in the presence of the TRPV1 antagonist IRTX $(300 \mathrm{nM})$. Application of IRTX reduced per se by $15 \pm 5.70 \%$ the frequency of spikes from $2.12 \pm 0.27$ to $1.77 \pm 0.22 \mathrm{~Hz} \quad(n=7, p<0.05)$. Subsequent perfusion of CAPS $3 \mu \mathrm{M}$ did not significantly change the firing frequency in all tested neurons $(1.77 \pm 0.22 \mathrm{~Hz}$ control in IRTX $v s$ $1.79 \pm 0.30 \mathrm{~Hz}$ added CAPS; $p=0.789, n=7$, Figure $1 \mathrm{~b}$ ).

The role of glutamatergic transmission in the CAPSinduced excitation was evaluated in eight neurons. Four out of eight DA cells were perfused with CAPS $3 \mu \mathrm{M}$ and then exposed to ionotropic glutamate antagonists (Figure 2). Under these conditions, CAPS induced an increase in firing that readily reversed in $6.74 \pm 0.16 n$ min of superfusion with CNQX and AP5 ( $n=4$, Figure 2), whereas, in the absence of these ionotropic glutamate antagonists, the CAPS-induced effects did not reverse even after 20-30 min of wash. In the remnant 4DA neurons, incubated for 8-10 min with CNQX and AP5, the subsequent application of CAPS $3 \mu \mathrm{M}$ did not significantly modify the firing frequency (from $0.75 \pm 0.17$ to $0.71 \pm 0.22 \mathrm{~Hz}, p=0.929$ ).

\section{Capsaicin and Noxious Stimuli Increase Dopamine Efflux}

$D A$ response in CAPS and IRTX + CAPS groups. The effects of CAPS and IRTX + CAPS injection on DA release in

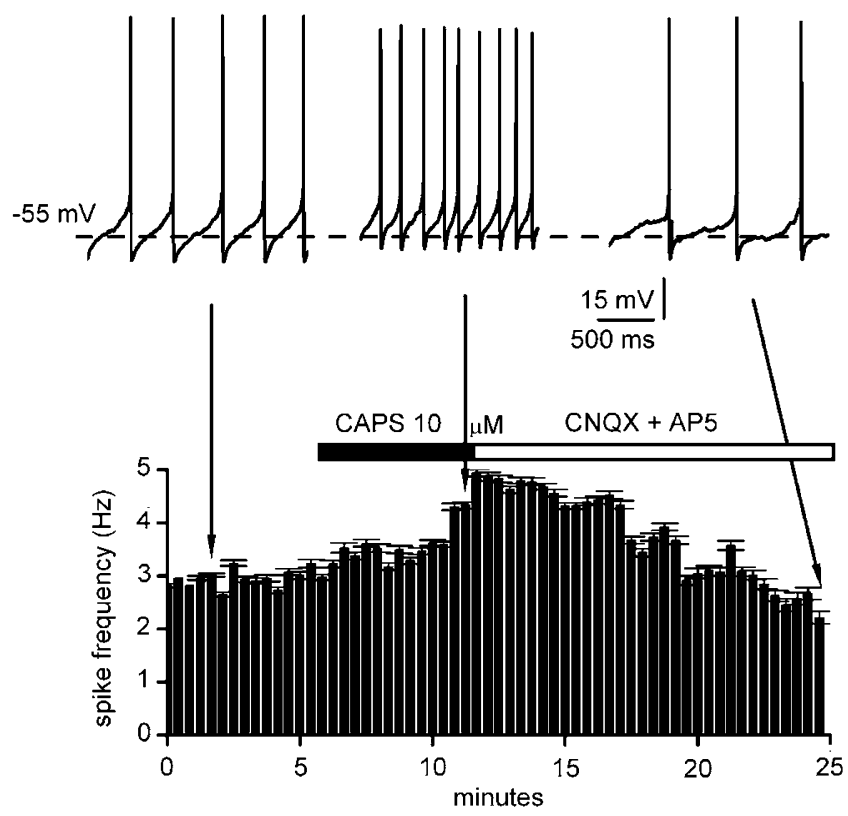

Figure 2 Capsaicin augments the discharge of DA neurons by activating glutamatergic neurotransmission. Top, traces: current-clamp recordings of a single neuron in control (left panel), under CAPS perfusion (middle panel), and in the presence of the ionotropic glutamate receptor antagonist CNQX (I0 $\mu \mathrm{M})$ and AP5 $(50 \mu \mathrm{M})$ (right panel). Bottom, running frequency histogram showing the time-course of effects of CAPS on the same neuron shown on the top. Note that the excitatory effects of CAPS rapidly reversed in the presence of CNQX and AP5. This effect was significantly different from the irreversible effect of CAPS perfused alone $\left(\chi^{2}\right.$ twopopulation $p<0.05$ ).

NAc are shown in Figure 3. Statistical analyses revealed a significant interaction between treatment and time $\left(\mathrm{F}_{(10,60)}=2.77 ; p<0.01\right)$. A simple effect analysis revealed a significant effect of time only for CAPS at 8, 16, and 24 min, and a maximal increase of DA compared with veh at $16 \mathrm{~min}(\sim 60 \%)$. No significant differences between veh and CAPS + IRTX were evident.

Thus, CAPS injection in VTA produces a significant increase of DA release in the NAc, while simultaneous IRTX injection counteracts the CAPS excitatory effect.

$D A$ response in shock and IRTX + shock groups. The effects of shock and IRTX + shock on DA release in the NAc are shown in Figure 4. Statistical analyses revealed a significant treatment $\times$ time interaction $\left(\mathrm{F}_{(7,56)}=3.67\right.$, $p<0.01)$. A simple effect analysis revealed a significant effect of time only for shock-induced DA release. Veh + shock group showed significant, time-dependent increase of DA outflow, reaching maximal DA increase $32 \min (\sim 50 \%)$ after shock administration. No significant increase in DA outflow was evident in the IRTX + shock group.

These results show that the increase in DA outflow in NAc that resulted by tail-shock administration has been completely prevented by IRTX injection in the VTA.

\section{DISCUSSION}

This is the first study examining the excitatory effect of TRPV1 receptor activation on the firing activity of DA cells 


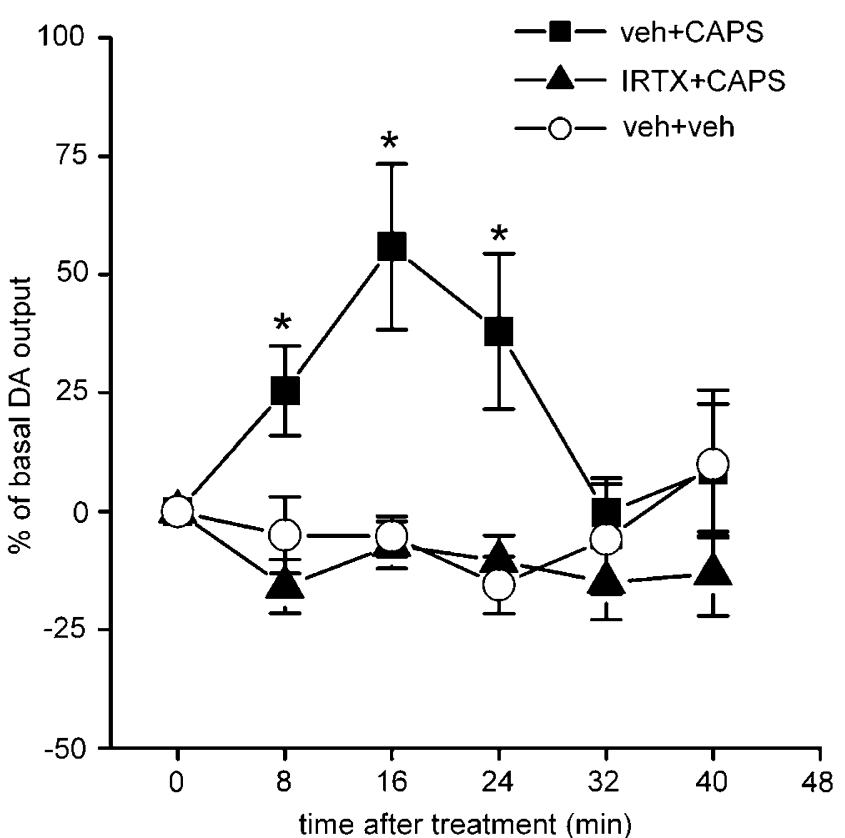

Figure 3 The effects of veh $(0.01 \%$ of ethanol, $n=5)$, CAPS $50 \mu \mathrm{M}$ $(n=5)$, and IRTX I $\mu M+$ CAPS $50 \mu M(n=5)$ injection on DA release in $\mathrm{NAc}$. Results are expressed as percentage changes (means \pm SE) from basal values $(3.26 \pm 0.33 \mathrm{pg} / 20 \mu \mathrm{l})$. Statistical analyses were performed on raw data. $* p<0.005$ compared with vehicle.

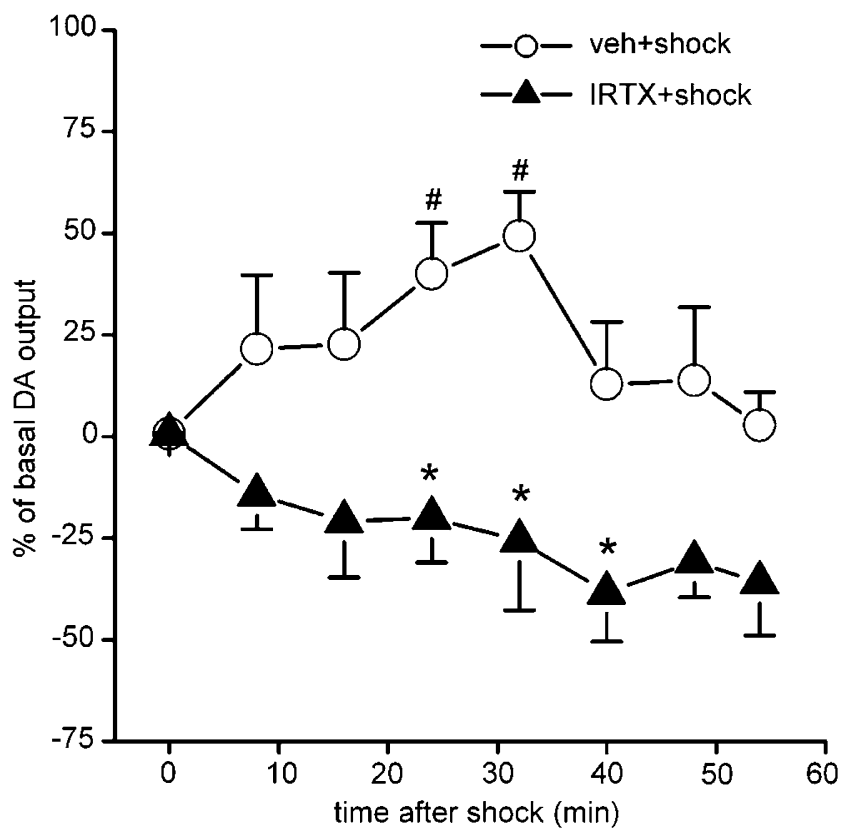

Figure 4 The effects of shock $(n=5)$ and IRTX | $\mu M+\operatorname{shock}(n=5)$ on $\mathrm{DA}$ release in NAc. Results are expressed as percentage changes (means \pm SE) from basal values $(3.65 \pm 0.43 \mathrm{pg} / 20 \mu \mathrm{l})$. Statistical analyses were performed on raw data. $* 0<0.05$ compared with the shock + veh group; ${ }^{\#}<0.05$ compare with the basal values.

within the VTA and on the release of dopamine within the NAc following a noxious stimulus.

It appears that the increased firing rate caused by the TRPV1 agonist, CAPS, is due to an indirect mechanism onto DA neurons. Specifically, it is caused by an enhanced glutamatergic transmission onto these neurons, since the glutamatergic ionotropic antagonists reduced the capsaicininduced excitatory effect. Interestingly, we also observed a TRPV1-mediated burst-firing pattern in a significant amount of spontaneously active DA neurons ( $44 \%$ of cells) treated with CAPS 3 and $10 \mu \mathrm{M}$.

The increase in neuronal firing caused by CAPS has been previously reported in an in vivo study in the locus coeruleus (Hajos et al, 1987), confirming the increase of adrenergic neurotransmission induced by CAPS (Watanabe et al, 2001; Marinelli et al, 2002). Collectively, these studies support the idea that stimulation of central TRPV1 can alter the discharge of aminergic neurons in order to modulate more efficiently the release of neurotransmitters into target areas (Manley et al, 1992; Suaud-Chagny et al, 1992). Moreover, it is generally accepted that bursting events can lead to a much larger DA efflux than a regular spontaneous activity in dopaminergic cells (Gonon, 1988; Garris et al, 1994) and, in this regard, we observed that CAPS promotes a transition from single to burst firing. However, enhanced activity in the single-spike mode could also be important in releasing DA, as observed in a previous study (Floresco et al, 2003).

The increase in DA efflux within the NAc produced by injection of CAPS into the VTA is consistent with the CAPS-induced changes in firing rate observed in the in vitro experiments. It is interesting to note that previous studies have also reported that intranigral injection of CAPS enhances locomotor activity and this could result from an augmented release of DA (Dawbarn et al, 1981).

In agreement with a previous report (Yalid et al, 2001), a short-lasting tail shock produced a delayed increase of DA release in the NAc. In the present study, this increase was prevented by concomitant intra-VTA administration of the TRPV1 antagonist IRTX, indicating that acute stressful stimuli could impose changes in dopaminergic functions through TRPV1 activation. Noticeably, both the increased firing frequency of DA neurons following superfusion of CAPS and the release of DA caused either by local application of CAPS, or by tail shock, were abolished by the co-application of IRTX. Consistent with previous findings (Marinelli et al, 2003), IRTX decreased per se the release of DA into the NAc (as shown in Figure 4) and the firing frequency of DA neurons, suggesting a tonic control of the discharge activity by TRPV1. Thus, the pharmacology of the in vivo and in vitro experiments is consistent with TRPV1-mediated actions.

Our data provide evidence that a peripheral aversive stimulus can activate TRPV1 receptors located in the VTA, where they cause neuronal activation and DA release.

Although the mesolimbic dopamine system is known to play a crucial role in the detection of reward salience and/or the incentive motivation that precedes the earning of reward (Wise, 2004), several reports have demonstrated DA release in response to aversive stimuli in animals and recently also in humans, suggesting an involvement of this neuronal circuit in both appetitive and aversive conditions (Berridge and Robinson, 1998; Pruessner et al, 2004). The present observations suggest that the responses to painful stimulation depend upon the activation of TRPV1 receptors within the VTA. 
These observations are in agreement with prior studies, which have reported that noxious stimuli applied to the tail increase spike firing (Maeda and Mogenson, 1982; Mantz et al, 1989; Gao et al, 1990) and c-fos proto-oncogene expression in midbrain dopaminergic cells (Ma et al, 1993). One of the mechanisms responsible for these changes of firing rate could be an activation of excitatory inputs on DA cells caused by TRPV1 stimulation (Marinelli et al, 2003).

It is known that the glutamatergic inputs to the VTA that cause neuronal excitation could arise from the PFC, several subdivisions of amygdaloid complex, and the peduncolopontine nucleus (Jackson and Crossman, 1983; Christie et al, 1985; McDonald, 1996). Interestingly, the PFC and the amygdaloid nuclei express TRPV1 (Mezey et al, 2000; Szabo et al, 2002; Roberts et al, 2004) and both areas can be activated by stressful and noxious events (Herman et al, 1982; Abercrombie et al, 1989; Coco et al, 1992), producing changes in the mesolimbic dopamine system that are required for aversive responses (Kim et al, 2004).

In conclusion, we have presented for the first time that TRPV1 activation in the brain is related to the dopamine release, following a painful stimulus.

\section{ACKNOWLEDGEMENTS}

We thank Dr Christopher Vaughan and Dr Ezia Guatteo for reading the manuscript and for their useful comments on these experiments.

\section{REFERENCES}

Abercrombie ED, Keefe KA, DiFrischia DS, Zigmond MJ (1989). Differential effect of stress on in vivo dopamine release in striatum, nucleus accumbens, and medial frontal cortex. J Neurochem 52: 1655-1658.

Berridge KC, Robinson TE (1998). What is the role of dopamine in reward: hedonic impact, reward learning, or incentive salience? Brain Res Brain Res Rev 28: 309-369.

Bonci A, Bernardi G, Grillner P, Mercuri NB (2003). The dopamine-containing neuron: maestro or simple musician in the orchestra of addiction? Trends Pharmacol Sci 24: 172-177.

Cabib S, Puglisi-Allegra S (1994). Opposite responses of mesolimbic dopamine system to controllable and uncontrollable aversive experiences. J Neurosci 14: 3333-3340.

Christie MJ, Bridge S, James LB, Beart PM (1985). Excitotoxin lesions suggest an aspartatergic projection from rat medial prefrontal cortex to ventral tegmental area. Brain Res 333: 169-172.

Coco ML, Kuhn CM, Ely TD, Kilts CD (1992). Selective activation of mesoamygdaloid dopamine neurons by conditioned stress: attenuation by diazepam. Brain Res 590: 39-47.

Dawbarn D, Harmar AJ, Pycock CJ (1981). Intranigral injection of capsaicin enhances motor activity and depletes nigral 5hydroxytryptamine but not substance P. Neuropharmacology 20: 341-346.

Di Chiara G, Acquas E, Tanda G, Cadoni C (1993). Drugs of abuse: biochemical surrogates of specific aspects of natural reward? Biochem Soc Symp 59: 65-81.

Doyle MW, Bailey TW, Jin YH, Andresen MC (2002). Vanilloid receptors presynaptically modulate cranial visceral afferent synaptic transmission in nucleus tractus solitarius. $J$ Neurosci 22: 8222-8229.
Finlay JM, Zigmond MJ (1997). The effects of stress on central dopaminergic neurons: possible clinical implications. Neurochem Res 22: 1387-1394.

Floresco SB, West AR, Ash B, Moore H, Grace AA (2003). Afferent modulation of dopamine neuron firing differentially regulates tonic and phasic dopamine transmission. Nat Neurosci 6: 968-973.

Gao DM, Jeaugey L, Pollak P, Benabid AL (1990). Intensitydependent nociceptive responses from presumed dopaminergic neurons of the substantia nigra, pars compacta in the rat and their modification by lateral habenula inputs. Brain Res 529: 315-319.

Garris PA, Ciolkowski EL, Pastore P, Wightman RM (1994). Efflux of dopamine from the synaptic cleft in the nucleus accumbens of the rat brain. J Neurosci 14: 6084-6093.

Gonon FG (1988). Nonlinear relationship between impulse flow and dopamine released by rat midbrain dopaminergic neurons as studied by in vivo electrochemistry. Neuroscience 24: 19-28.

Grace AA, Onn SP (1989). Morphology and electrophysiological properties of immunocytochemically identified rat dopamine neurons recorded in vitro. J Neurosci 9: 3463-3481.

Grillner P, Mercuri NB (2002). Intrinsic membrane properties and synaptic inputs regulating the firing activity of the dopamine neurons. Behav Brain Res 130: 149-169.

Guarraci FA, Kapp BS (1999). An electrophysiological characterization of ventral tegmental area dopaminergic neurons during differential pavlovian fear conditioning in the awake rabbit. Behav Brain Res 99: 169-179.

Hajos M, Jancso G, Engberg G (1987). Capsaicin-induced excitation of locus coeruleus neurons. Acta Physiol Scand 129: 415-420.

Herman JP, Guillonneau D, Dantzer R, Scatton B, SemerdjianRouquier L, Le Moal M (1982). Differential effects of inescapable footshocks and of stimuli previously paired with inescapable footshocks on dopamine turnover in cortical and limbic areas of the rat. Life Sci 30: 2207-2214.

Hollerman JR, Schultz W (1998). Dopamine neurons report an error in the temporal prediction of reward during learning. Nat Neurosci 1: 304-309.

Horger BA, Roth RH (1996). The role of mesoprefrontal dopamine neurons in stress. Crit Rev Neurobiol 10: 395-418.

Jackson A, Crossman AR (1983). Nucleus tegmenti pedunculopontinus: efferent connections with special reference to the basal ganglia, studied in the rat by anterograde and retrograde transport of horseradish peroxidase. Neuroscience 10: 725-765.

Johnson SW, North RA (1992). Two types of neurone in the rat ventral tegmental area and their synaptic inputs. J Physiol 450: 455-468.

Kim JA, Pollak KA, Hjelmstad GO, Fields HL (2004). A single cocaine exposure enhances both opioid reward and aversion through a ventral tegmental area-dependent mechanism. Proc Natl Acad Sci USA 101: 5664-5669. Epub 2004 April 5662.

Ma QP, Zhou Y, Han JS (1993). Electroacupuncture accelerated the expression of c-Fos protooncogene in dopaminergic neurons in the ventral tegmental area of the rat. Int J Neurosci 70: 217-222.

Maeda H, Mogenson GJ (1982). Effects of peripheral stimulation on the activity of neurons in the ventral tegmental area, substantia nigra and midbrain reticular formation of rats. Brain Res Bull 8: 7-14.

Manley LD, Kuczenski R, Segal DS, Young SJ, Groves PM (1992). Effects of frequency and pattern of medial forebrain bundle stimulation on caudate dialysate dopamine and serotonin. J Neurochem 58: 1491-1498.

Mantz J, Thierry AM, Glowinski J (1989). Effect of noxious tail pinch on the discharge rate of mesocortical and mesolimbic dopamine neurons: selective activation of the mesocortical system. Brain Res 476: 377-381. 
Marinelli S, Di Marzo V, Berretta N, Matias I, Maccarrone M, Bernardi $G$ et al (2003). Presynaptic facilitation of glutamatergic synapses to dopaminergic neurons of the rat substantia nigra by endogenous stimulation of vanilloid receptors. J Neurosci 23: 3136-3144.

Marinelli S, Vaughan CW, Christie MJ, Connor M (2002). Capsaicin activation of glutamatergic synaptic transmission in the rat locus coeruleus in vitro. J Physiol 543: 531-540.

McDonald AJ (1996). Glutamate and aspartate immunoreactive neurons of the rat basolateral amygdala: colocalization of excitatory amino acids and projections to the limbic circuit. J Comp Neurol 365: 367-379.

Mercuri NB, Bonci A, Calabresi P, Stefani A, Bernardi G (1995). Properties of the hyperpolarization-activated cation current Ih in rat midbrain dopaminergic neurons. Eur J Neurosci 7: 462-469.

Mezey E, Toth ZE, Cortright DN, Arzubi MK, Krause JE, Elde R et al (2000). Distribution of mRNA for vanilloid receptor subtype 1 (VR1), and VR1-like immunoreactivity, in the central nervous system of the rat and human. Proc Natl Acad Sci USA 97: $3655-3660$.

Moore H, Rose HJ, Grace AA (2001). Chronic cold stress reduces the spontaneous activity of ventral tegmental dopamine neurons. Neuropsychopharmacology 24: 410-419.

O’Neil RG, Brown RC (2003). The vanilloid receptor family of calcium-permeable channels: molecular integrators of microenvironmental stimuli. News Physiol Sci 18: 226-231.

Overton PG, Clark D (1997). Burst firing in midbrain dopaminergic neurons. Brain Res Brain Res Rev 25: 312-334.

Paxinos G, Watson C (1982). The Rat Brain in Stereotaxic Coordinates. Academic Press: Sydney.

Phillips AG, Ahn S, Howland JG (2003). Amygdalar control of the mesocorticolimbic dopamine system: parallel pathways to motivated behavior. Neurosci Biobehav Rev 27: 543-554.

Pontieri FE, Tanda G, Di Chiara G (1995). Intravenous cocaine, morphine, and amphetamine preferentially increase extracellular dopamine in the 'shell' as compared with the 'core' of the rat nucleus accumbens. Proc Natl Acad Sci USA 92: 12304-12308.

Prisco S, Natoli S, Bernardi G, Mercuri NB (2002). Group I metabotropic glutamate receptors activate burst firing in rat midbrain dopaminergic neurons. Neuropharmacology 42: 289-296.

Pruessner JC, Champagne F, Meaney MJ, Dagher A (2004). Dopamine release in response to a psychological stress in humans and its relationship to early life maternal care: a positron emission tomography study using [11C]raclopride. J Neurosci 24: 2825-2831.

Roberts JC, Davis JB, Benham CD (2004). [3H]Resiniferatoxin autoradiography in the CNS of wild-type and TRPV1 null mice defines TRPV1 (VR-1) protein distribution. Brain Res 995: 176-183.

Sasamura T, Sasaki M, Tohda C, Kuraishi Y (1998). Existence of capsaicin-sensitive glutamatergic terminals in rat hypothalamus. Neuroreport 9: 2045-2048.

Schmidt WJ (1998). Dopamine-glutamate interactions in the basal ganglia. Amino Acids 14: 5-10.

Schultz W (1986). Responses of midbrain dopamine neurons to behavioral trigger stimuli in the monkey. J Neurophysiol 56: 1439-1461.

Shepard PD, Bunney BS (1991). Repetitive firing properties of putative dopamine-containing neurons in vitro: regulation by an apamin-sensitive $\mathrm{Ca}(2+)$-activated $\mathrm{K}+$ conductance. Exp Brain Res 86: 141-150.

Suaud-Chagny MF, Chergui K, Chouvet G, Gonon F (1992). Relationship between dopamine release in the rat nucleus accumbens and the discharge activity of dopaminergic neurons during local in vivo application of amino acids in the ventral tegmental area. Neuroscience 49: 63-72.

Szabo T, Biro T, Gonzalez AF, Palkovits M, Blumberg PM (2002). Pharmacological characterization of vanilloid receptor located in the brain. Brain Res Mol Brain Res 98: 51-57.

Ventura R, Cabib S, Alcaro A, Orsini C, Puglisi-Allegra S (2003). Norepinephrine in the prefrontal cortex is critical for amphetamine-induced reward and mesoaccumbens dopamine release. J Neurosci 23: 1879-1885.

Watanabe T, Sakurada N, Kobata K (2001). Capsaicin-, resiniferatoxin-, and olvanil-induced adrenaline secretions in rats via the vanilloid receptor. Biosci Biotechnol Biochem 65: 2443-2447.

Westerink BH, Enrico P, Feimann J, De Vries JB (1998). The pharmacology of mesocortical dopamine neurons: a dual-probe microdialysis study in the ventral tegmental area and prefrontal cortex of the rat brain. J Pharmacol Exp Ther 285: 143-154.

Wise RA (2002). Brain reward circuitry: insights from unsensed incentives. Neuron 36: 229-240.

Wise RA (2004). Dopamine, learning and motivation. Nat Rev Neurosci 5: 483-494.

Yalid G, Overstreet DH, Zangen A (2001). Limbic dopaminergic adaptation to a stressful stimulus in a rat model of depression. Brain Res 896: 43-47. 